\title{
Optimal dosage and route of administration of methotrexate in rheumatoid arthritis: a systematic review of the literature
}

\author{
K Visser, D van der Heijde
}

- Additional appendices are published online only at http:// ard.bmj.com/content/vol68/ issue 7

Department of Rheumatology, Leiden University Medical Center, Leiden, The Netherlands

Correspondence to:

Dr K Visser, Leiden University Medical Center, Department of Rheumatology, C1-R, P0 Box 9600, 2300 RC Leiden, The Netherlands; K.Visser@lumc.nl

Accepted 17 November 2008 Published Online First 25 November 2008

\begin{abstract}
Objectives: To review systematically the available literature on the optimal dosage and route of administration of methotrexate in patients with rheumatoid arthritis (RA), as an evidence base for generating clinical practice recommendations.
\end{abstract}

Methods: A systematic literature search was carried out in MEDLINE, EMBASE, Cochrane Library and American College of Rheumatology/European League Against Rheumatism meeting abstracts, searching for randomised controlled trials evaluating various dosages or routes of administration of methotrexate in RA. Articles that fulfilled predefined inclusion criteria were systematically reviewed and the quality was appraised. Effect sizes and odds ratios for clinical, radiological and toxicity outcomes were calculated and directly or indirectly compared between study groups using methotrexate in different dosages or by different routes.

Results: A total of 38 publications out of 1748 identified references was included in the review. Start doses of $25 \mathrm{mg} /$ week or fast escalation with $5 \mathrm{mg} /$ month to 25 $30 \mathrm{mg} /$ week were associated with higher clinical effect sizes and more (gastrointestinal) adverse events in comparison with doses of 5-15 mg/week or slow escalation. Starting with $15 \mathrm{mg} /$ week subcutaneous versus oral methotrexate was associated with higher clinical efficacy but more withdrawal due to toxicity in early RA. In longstanding RA, after failure on 15-20 mg/ week orally, a switch to $15 \mathrm{mg} /$ week intramuscularly with subsequent dose escalation did not result in increased efficacy.

Conclusions: Starting on methotrexate $15 \mathrm{mg} /$ week orally, escalating with $5 \mathrm{mg} / \mathrm{month}$ to $25-30 \mathrm{mg} /$ week, or the highest tolerable dose, with a subsequent switch to subcutaneous administration in the case of an insufficient response, seems to be the optimal evidence-based dosing and routing recommendation for methotrexate in RA.

Methotrexate is widely used as the disease modifying antirheumatic drug (DMARD) of first choice in the treatment of rheumatoid arthritis (RA), because it is effective, has an acceptable toxicity profile and has low costs. ${ }^{1-3}$ Despite more than two decades of experience, considerable variability exists in the way rheumatologists prescribe methotrexate therapy, including the dosage and route of administration. More knowledge on the optimal use is needed, as this would benefit RA patients, improve education and facilitate treatment evaluation.

This paper is part of the $3 \mathrm{E}$ (evidence, expertise, exchange) Initiative. This $3 E$ Initiative and the resulting recommendations for the use of methotrexate are described in more detail in the same issue of this journal. ${ }^{4}$ The objective of the current work was to review systematically the available literature concerning one of the 10 selected questions as an evidence base for generating the recommendations. The question was: "What is the best dosing strategy and route of administration of methotrexate in patients with RA to optimise rapid, early, clinical and radiographic response and minimise toxicity?"

\section{METHODS}

The systematic literature review was carried out in several steps following the updated guidelines for Cochrane systematic reviews. ${ }^{5}$

\section{Rephrasing research question}

The clinical question as formulated by the experts was translated into an epidemiological research question according to the PICO (patient, intervention, comparator, outcome) method. ${ }^{6}$ Patients were defined as adults with RA according to the American College of Rheumatology (ACR) criteria. $^{7}$ The intervention was defined as methotrexate in a certain dosage (separate for start, escalation and target dose) and a certain route of administration (oral, subcutaneous, intramuscular or intravenous), with a different dosage or route as comparator. Outcomes were threefold: clinical efficacy measures among swollen joint count (SJC), tender joint count (TJC), disease activity score (DAS), ACR20/50/70 response, visual analogue scale for patient-reported outcomes, health assessment questionnaire and erythrocyte sedimentation rate; radiological progression and system-specific adverse events including withdrawal due to toxicity. Effect sizes and odds ratios (OR) were anticipated effect parameters. The final search question was thus rephrased as: What is the difference in effect size and OR for short-term clinical, radiographic and toxicity outcomes in RA patients on various dosages and routes of administration of methotrexate?

\section{Scenarios}

In the optimal scenario we anticipated to find randomised controlled trials (RCT) directly comparing different dosages or routes of methotrexate administration. The suboptimal scenario included RCT evaluating methotrexate monotherapy versus placebo, another DMARD, a biological, or a combination of DMARD without methotrexate. By grouping the trials per comparator drug, potential indirect comparisons between various 
Table 1 Study and patient characteristics of trials included for direct comparisons of methotrexate dosages/ routes

\begin{tabular}{|c|c|c|}
\hline $\begin{array}{l}\text { Study reference, design and } \\
\text { quality }\end{array}$ & Patient characteristics & Treatment groups (methotrexate dosage/route) \\
\hline \multicolumn{3}{|l|}{ Furst et al, $1989^{8}$} \\
\hline Double-blind RCT & $\mathrm{n}=52$ & Oral methotrexate $20 \mathrm{mg} / \mathrm{m}^{2} /$ week $\approx 25-35 \mathrm{mg} /$ week \\
\hline 16-Week follow-up & RA 4.8 years & Oral methotrexate $10 \mathrm{mg} / \mathrm{m}^{2} /$ week $\approx 12.5-20 \mathrm{mg} /$ week \\
\hline van Tulder score 10 & Failed gold or & Oral methotrexate $5 \mathrm{mg} / \mathrm{m}^{2} /$ week $\approx 5-10 \mathrm{mg} /$ week \\
\hline \multirow[t]{2}{*}{ Evidence level $2 b$} & D-Penicillamine & Placebo \\
\hline & Methotrexate-naive & No folic acid \\
\hline Schnabel et al, $1994^{9}$ & $\mathrm{n}=185$ & Oral methotrexate $25 \mathrm{mg} /$ week \\
\hline Open-label RCT & RA 3-10 years & Oral methotrexate $15 \mathrm{mg} /$ week \\
\hline 52-Week follow-up & Previous DMARD & Increase or decrease if necessary \\
\hline van Tulder score 7 & Methotrexate-naive & No folic acid \\
\hline \multicolumn{3}{|l|}{ Evidence level $2 b$} \\
\hline Verstappen et al, $2007^{10}$ & $\mathrm{n}=299$ & Fast escalation: oral methotrexate $7.5 \mathrm{mg} /$ week+ \\
\hline Open-label RCT & $\mathrm{RA}<1$ year & $5 \mathrm{mg} / \mathrm{month}$ to mean max $25 \mathrm{~g} /$ week $(\max 30)$ \\
\hline 52-Week follow-up & DMARD-naive & Slow escalation: oral methotrexate $7.5 \mathrm{mg} /$ week+ \\
\hline van Tulder score 7 & & $5 \mathrm{mg} / 3$ months to mean max $18 \mathrm{mg} /$ week \\
\hline Evidence level 2b & & Folic acid \\
\hline Lambert et al, 2004" & $\mathrm{n}=54$ & Switch to intramuscular methotrexate: \\
\hline Double-blind RCT & RA 10 years & $15 \mathrm{mg} /$ week+ escalation $5 \mathrm{mg} /$ month to max $45 \mathrm{mg} /$ week \\
\hline 22-Week follow-up & Failed oral methotrexate & $15 \mathrm{mg} /$ week+ placebo escalation \\
\hline van Tulder score 9 & 15-20 mg/week & Folic acid \\
\hline \multicolumn{3}{|l|}{ Evidence level $2 \mathrm{~b}$} \\
\hline Braun et al, $2008^{12}$ & $\mathrm{n}=375$ & Subcutaneous methotrexate $15 \mathrm{mg} /$ week, escalation to \\
\hline Double-blind RCT & $\mathrm{RA}<1$ years & $20 \mathrm{mg} /$ week if no ACR20 at 16 weeks \\
\hline $\begin{array}{l}\text { 24-Week follow-up } \\
\text { van Tulder score } 11\end{array}$ & Methotrexate-naive & $\begin{array}{l}\text { Oral methotrexate } 15 \mathrm{mg} / \text { week, switch to } 15 \mathrm{mg} / \text { week } \\
\text { subcutaneously if no ACR20 at } 16 \text { weeks }\end{array}$ \\
\hline Evidence level $1 \mathrm{~b}$ & & Folic acid \\
\hline
\end{tabular}

ACR, American College of Rheumatology; DMARD, disease-modifying antirheumatic drug; RA, rheumatoid arthritis; RCT, randomised controlled trial.

methotrexate schedules were anticipated. The condition for these indirect comparisons was a homogeneous response in the comparator arms within the grouped trials. Observational studies represented the least optimal scenario, as these inherently introduce methodological limitations.

\section{Systematic literature search}

A systematic literature search for articles published between 1950 and September 2007 was carried out in MEDLINE, EMBASE and the Cochrane Library, using a comprehensive search strategy (appendix 1 of the online only version of this paper) in collaboration with an experienced librarian. ${ }^{13}$ The European League Against Rheumatism (EULAR) 2005-7 and ACR 2005-6 meeting abstracts were also searched. The search was limited to RCT, using a modification of the Cochrane highly sensitive search strategy. ${ }^{14}$ No language restriction was used. Review articles were also retrieved for identifying additional references via hand search.

\section{Selection of articles}

Relevant articles were selected in a systematic two-step procedure. First, titles and abstracts of all identified references were screened, excluding articles that clearly did not address the topic of interest. Second, selected articles were reviewed in full paper, applying the following inclusion criteria: RCT, RA 18 years old or greater, monotherapy methotrexate in one of the treatment groups, data on dosage and route and data on one or more of the prespecified outcome measures. Articles that did not fulfil all the inclusion criteria or had insufficient data for analysis were excluded from the systematic review.

\section{Data extraction and quality appraisal}

Publication details, patient characteristics, dosage and route of methotrexate and data on relevant outcomes were extracted from all the included articles using standard forms. Data from non-English language publications were extracted by reviewers from the international panel of the $3 E$ Initiative. If necessary, authors were contacted to provide additional information. The methodological quality of each RCT was graded by a scale according to van Tulder et al, ${ }^{5}$ with a maximum score of 11 points. The points were subsequently translated into levels of evidence according to the Oxford Centre for Evidence-based Medicine, ${ }^{15}$ a summary of which can be found in appendix 2 of the online version of this paper.

\section{Data-analysis}

For continuous variables, three types of effect size were calculated for the difference between baseline and the end of trial data. ${ }^{16}{ }^{17}$ Per treatment group, the effect size and the standardised response mean (SRM) were calculated as the mean change in score divided by the baseline standard deviation (SD) (effect size) or the mean change divided by the SD of the change (SRM). To compare the effect between two treatment groups, the pooled Cohen's effect size was calculated as the mean change in the index group minus the mean change in the comparator group divided by a pooled baseline SD. The corresponding $95 \% \mathrm{CI}$ was constructed and indicates a statistically significant effect at the $5 \%$ level if zero is outside the interval. ${ }^{18}$ In accordance with the literature, we considered an effect size of approximately 0.2 as small, of approximately 0.5 as moderate and greater than 0.8 as large, with negative effect sizes indicating worsening. For dichotomous data, OR 

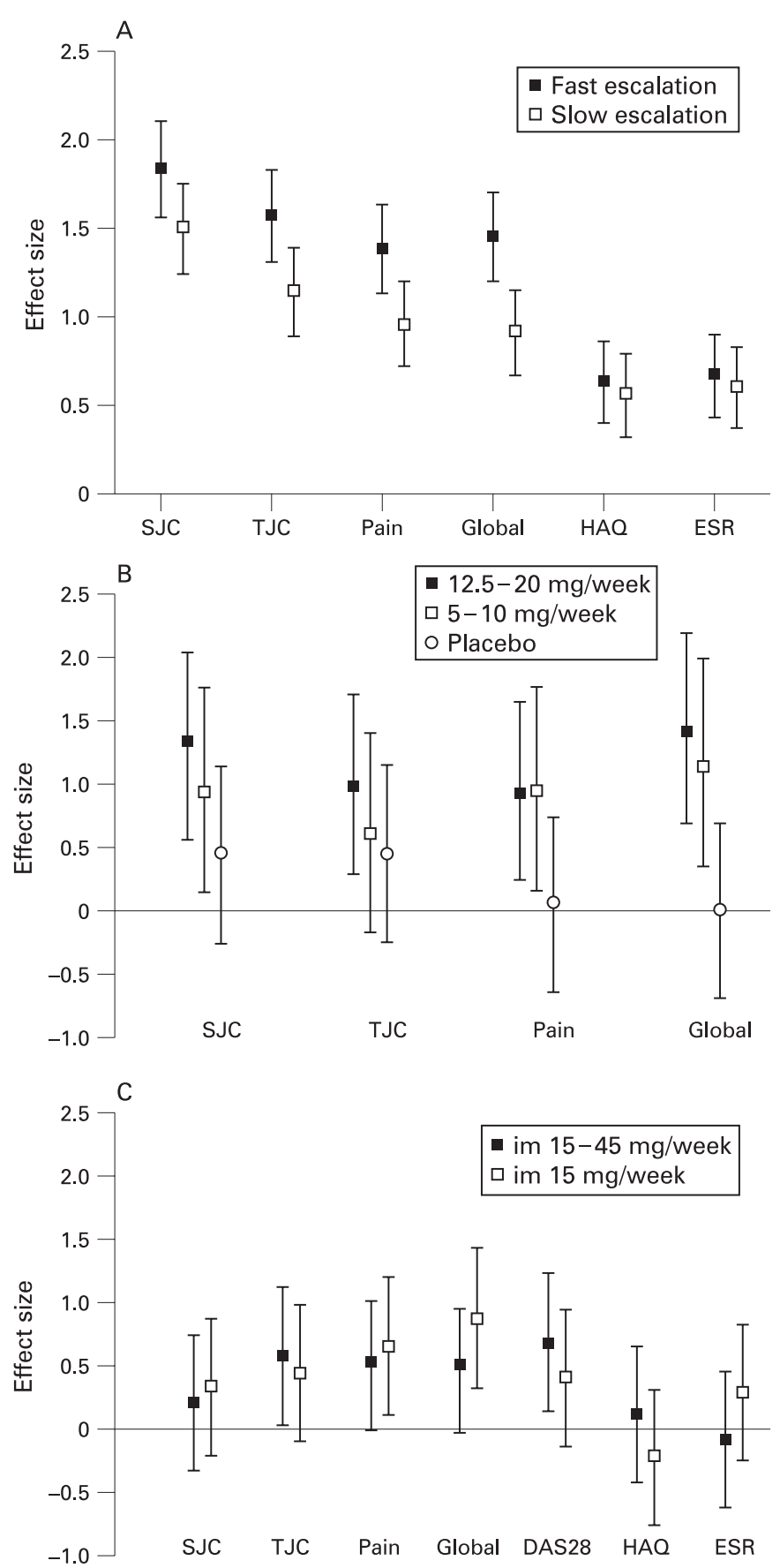

Figure 1 Effect sizes $(95 \% \mathrm{Cl})$ of clinical variables per treatment group of studies directly comparing different dosages/routes. DAS28, disease activity score in 28 joints; ESR, erythrocyte sedimentation rate; $\mathrm{HAO}$, health assessment questionnaire; im, intramuscular; SJC, swollen joint count; TJC, tender joint count.

(95\% CI) were calculated for the occurrence of system-specific adverse events. Intention to treat data were used if available.

\section{RESULTS}

A total of 1748 references was identified with the systematic search strategy. After title and abstract screening, 86 articles were retrieved for full paper review, of which 45 fulfilled the inclusion criteria. Two congress abstracts, which described a trial yet to be published ${ }^{12}$ and three additional papers from the hand search, of which one was not found in the databases, ${ }^{19}$ were also included. In conclusion, 50 references were included in the systematic review. A detailed flowchart with excluded references can be found in appendix 3 of the online only version of this paper.

The 50 references described 38 original trials, which were grouped according to the anticipated scenarios. For the optimal scenario, eight RCT that directly compared oral methotrexate in different dosages $(n=3),{ }^{8-10}$ intramuscular methotrexate in different dosages $(\mathrm{n}=1){ }^{11}$ methotrexate oral versus the subcutaneous route $(\mathrm{n}=1){ }^{12}$ or methotrexate weekly versus non-weekly $(\mathrm{n}=3)^{20-22}$ were found. The suboptimal scenario included 30 RCT evaluating methotrexate monotherapy versus placebo $(\mathrm{n}=5)$, DMARD monotherapy ( $\mathrm{n}=21)$, combination therapy $(\mathrm{n}=1)$ or anti-tumour necrosis factor $(\mathrm{n}=3)$ (references available online only in appendix 4).

\section{Direct comparisons oral methotrexate}

\section{Study characteristics}

The characteristics of the three RCT that directly compared different dosages of oral methotrexate are shown in table $1 .^{8-10}$ Furst et $\mathrm{al}^{\mathrm{B}}$ evaluated start doses of 5-10 mg/week, $12.5-20 \mathrm{mg} /$ week and 25-35 mg/week (mean 8, 18 and $32 \mathrm{mg} /$ week, respectively) in longstanding RA patients who failed other DMARD. In a similar population, Schnabel et a $l^{9}$ evaluated a start dose of 15 or $25 \mathrm{mg} /$ week, with a possible increase or decrease in the case of insufficient efficacy or toxicity. In DMARD-naive, early RA patients, Verstappen et al ${ }^{10}$ compared an intensive treatment strategy according to a computerised model for disease activity with a conventional strategy according to common practice. This resulted in a fast escalation of methotrexate from $7.5 \mathrm{mg} /$ week with $5 \mathrm{mg} /$ month to a mean maximum of $25 \mathrm{mg} /$ week versus a slow escalation of $5 \mathrm{mg} / 3$ months to a mean maximum of $18 \mathrm{mg} /$ week.

\section{Study results}

Figure $1 \mathrm{~B}$ shows a clinical dose-effect relation with effect sizes ranging from $0-0.45$ in the placebo group, $0.60-1.13$ in the methotrexate $5-10 \mathrm{mg} /$ week group, to $0.92-1.41$ in the 12.5 $20 \mathrm{mg} /$ week group. Methotrexate $12.5-20 \mathrm{mg} /$ week had a significantly larger effect than placebo on TJC (pooled effect size 1.08; $95 \%$ CI 0.35 to 1.81), pain (pooled effect size $0.92 ; 95 \%$ CI 0.21 to 1.64) and global status (pooled effect size 1.58; $95 \%$ CI 0.80 to 2.37 ), whereas methotrexate $5-10 \mathrm{mg}$ /week only had a significantly higher effect than placebo on pain and global status (pooled effect size $0.81 ; 95 \%$ CI 0.05 to 1.57 and 1.26 ; $95 \%$ CI 0.46 to 2.06 , respectively). A dose-toxicity relation was also seen in the OR for patients with adverse events, gastrointestinal and mucocutaneous toxicity, with the highest OR for $25-35 \mathrm{mg} /$ week methotrexate (table 2). The pooled effect size of methotrexate $12.5-20 \mathrm{mg} /$ week versus $5-10 \mathrm{mg} /$ week ranged from 0.22 to 0.35 , indicating an additional effect of the higher dosed group, although not reaching statistical significance, whereas no increased toxicity was seen (table 2).

Despite the lack of clinical outcomes, Schnabel et al ${ }^{9}$ reported that $27 \%$ of the patients who started with $15 \mathrm{mg} /$ week needed a dose increase for inefficacy, compared with $3 \%$ of those who started with $25 \mathrm{mg} /$ week (OR 10; 95\% CI 2.9 to 33.3). Although a trend for more gastrointestinal toxicity was observed in the higher dosed group, the percentage of patients decreasing the dose due to toxicity was $9 \%$ in both groups (table 2). Finally, a mean tolerable effective dose of 17-20 mg/week was reached.

Larger effect sizes for clinical variables were found for fast escalation (range 1.38-1.83) than for slow escalation of 


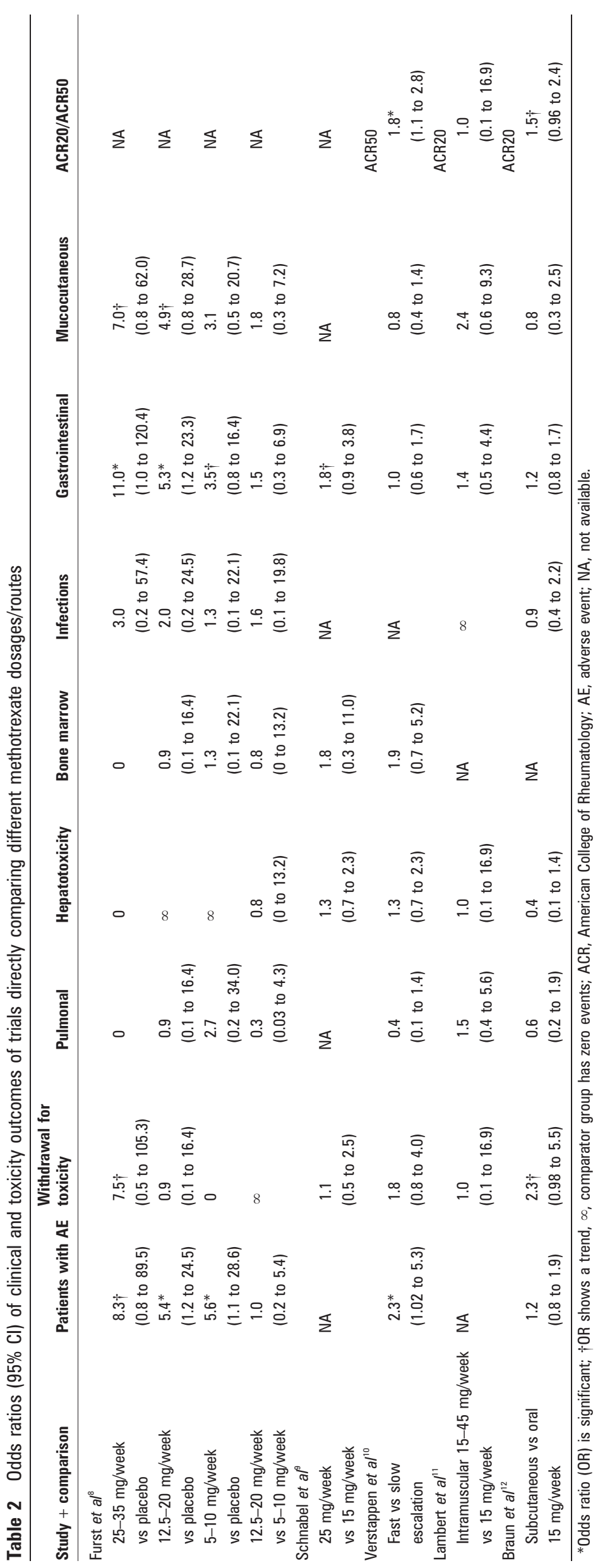


methotrexate (range 0.91-1.50) (fig 1A). SRM showed similar results (not shown). Differences in effect were significant as indicated by the pooled effect size for SJC (pooled effect size 0.33 ; $95 \%$ CI 0.10 to 0.56 ), TJC (pooled effect size 0.43 ; $95 \%$ CI 0.20 to 0.66 ), pain (pooled effect size 0.47 ; $95 \%$ CI 0.24 to 0.70 ) and global status (pooled effect size $0.49 ; 95 \%$ CI 0.26 to 0.72 ). Moreover, significantly more ACR50 responses were observed in the fast escalation group. Although in the fast escalation group significantly more patients experienced adverse events, the nature of the events was similar (table 2).

Only Verstappen et $a l^{10}$ and Schnabel et $a l^{9}$ reported radiological outcomes. In Verstappen et a ${ }^{10}$ no additional effect on radiological progression was seen of the fast in comparison with the slow escalation group (pooled effect size 0.05 ; $95 \%$ CI -0.23 to 0.33 ), whereas in Schnabel et al $25 \mathrm{mg} /$ week versus $15 \mathrm{mg} /$ week gave an OR of 0.4 (95\% CI 0.1 to 2.0) for the progression of joint damage in a selection of patients with less than 3 years disease duration.

\section{Direct comparisons parenteral methotrexate \\ Study characteristics}

Two RCT were found that evaluated parenteral methotrexate (table 1). ${ }^{11} 12$ longstanding RA patients who had failed on 15$20 \mathrm{mg} /$ week oral methotrexate and were switched to $15 \mathrm{mg} /$ week intramuscular methotrexate for 6 weeks, without achieving a DAS28 response, Lambert et al ${ }^{11}$ evaluated subsequent intramuscular placebo versus intramuscular methotrexate escalation up to $45 \mathrm{mg} /$ week. In contrast, Braun et a ${ }^{12}$ compared start doses of methotrexate $15 \mathrm{mg}$ /week subcutaneously versus orally in methotrexate-naive, early RA patients.

\section{Study results}

Small to moderate effect sizes for clinical variables were found in the methotrexate escalation group (range 0.09-0.67) and the placebo escalation group (range -0.22-0.82), without any significant differences between the groups (fig 1C). SRM showed similar results (not shown). The pooled effect size ranged from -0.38 in favour of the placebo group to 0.33 in favour of the escalation group. The ACR20 response in both groups was low (4\%) and toxicity was similar (table 2).

In contrast, significantly more patients who started subcutaneous methotrexate in Braun et al ${ }^{12}$ achieved an ACR20 response than those who started oral methotrexate $(85 \%$ vs $77 \%$, respectively, OR 1.7; 95\% CI 1.01 to 2.9 ) after 16 weeks. A trend for more ACR20 (OR 1.5; 95\% CI 0.96 to 2.4) and ACR70 response (OR 1.4; 95\% CI 0.9 to 2.1 ) after 24 weeks was also seen. However, patients on subcutaneous methotrexate more often discontinued therapy due to toxicity, without differences in the type of adverse event, including gastrointestinal toxicity (table 2).

\section{Indirect comparisons}

Indirect comparisons of the methotrexate arms of 30 trials grouped per comparator drug revealed uninformative, as methotrexate dosages or routes were not different, the clinical response to the comparator drugs showed large heterogeneity and outcome measures were not uniform. A summary is available in appendix 4 online only.

\section{Direct comparisons methotrexate frequencies}

In addition to the primary research question, three RCT directly comparing oral methotrexate weekly versus non-weekly were identified and included. ${ }^{20-22}$ The results can be found in appendix 5 available online only.

\section{DISCUSSION}

This systematic review summarises and evaluates the available evidence from the literature on the optimal dosage and route of administration of methotrexate in RA. Combined with the expert opinion of a broad panel of rheumatologists in the $3 \mathrm{E}$ Initiative, the results served as an evidence base for generating one of the 10 clinical recommendations for the use of methotrexate in rheumatic diseases. A detailed description of all final recommendations can be found elsewhere. ${ }^{4}$

The results showed that start doses of $25 \mathrm{mg} /$ week orally or fast dose escalation with $5 \mathrm{mg} / \mathrm{month}$ to $25-30 \mathrm{mg}$ /week were associated with higher efficacy, but also with more toxicity, in comparison with start doses of 5-15 mg/week or slow escalation with $5 \mathrm{mg} / 3$ months. ${ }^{8-10}$ These results strongly support reaching high (25-30 $\mathrm{mg} /$ week) doses in a short period of time for efficacy, but with toxicity as a limiting factor. The mean tolerable effective dose of 17-20 mg/week, after adjusting from 15 or $25 \mathrm{mg} /$ week starting dose in Schnabel et al, ${ }^{9}$ emphasises this efficacy/toxicity ratio. However, two of the reviewed studies lacked folic acid supplementation, which might increase the tolerability of higher dosages of methotrexate. As investigated concurrently in the $3 \mathrm{E}$ Initiative as a separate question, a meta-analysis of nine RCT indicated that folic acid reduces gastrointestinal and liver toxicity, without reducing efficacy. ${ }^{23}$ Therefore, as the primary aim of current RA treatment is achieving adequate undelayed disease control, the optimal evidence-based dosing strategy seems to be: starting with $15 \mathrm{mg} /$ week and escalating fast with $5 \mathrm{mg} / \mathrm{month}$ to $25-$ $30 \mathrm{mg} /$ week, although this should always be individually adapted to the level of disease activity and tolerability, including renal function. ${ }^{24}$

Although oral methotrexate is widely preferred, because of patients' preferences and low costs, the bioavailability of parenteral methotrexate is higher with increasing doses. ${ }^{25} 26$ Whether this leads to increased efficacy is addressed in only one RCT, which suggests that methotrexate $15 \mathrm{mg} /$ week subcutaneously is indeed associated with a better response compared with $15 \mathrm{mg}$ /week orally. ${ }^{12}$ However, escalating the oral dose to $25 \mathrm{mg} /$ week might also have increased clinical efficacy in this trial. This is supported by data from observational studies, in which patients switching from parenteral to oral methotrexate at an equal dose showed disease exacerbations, but not if the oral dose was $2.5-5 \mathrm{mg} /$ week higher. ${ }^{27}{ }^{28}$ In contrast, in longstanding RA patients who failed 15-20 mg/ week oral methotrexate plus other DMARD, neither a switch to $15 \mathrm{mg} /$ week intramuscularly, nor subsequent intramuscular dose escalation resulted in increased efficacy. ${ }^{11}$ However, for this selected population not responding well to conventional DMARD, therapy with biologicals is currently indicated. ${ }^{29}$ The evidence on toxicity associated with the parenteral use of methotrexate is inconsistent. Whereas more withdrawal due to toxicity, but similar adverse events were seen in the RCT from Braun et al, ${ }^{12}$ observational data suggest a decrease in (gastrointestinal) side effects administering methotrexate parenterally. ${ }^{27}$ Therefore, in summary, the preferred route of methotrexate seems to be oral, but a switch to subcutaneous is suggested in the case of an insufficient response at the highest tolerable oral dose.

The frequency of weekly dosing of methotrexate was inherited from the dermatological experience in the early 1980s. As the half-life of the active polyglutamate is 3 days, a 
twice weekly schedule was hypothesised to be more effective and less toxic, although it would also be less practical. ${ }^{30}$ However, Pandya et $a^{22}$ showed that a twice weekly schedule of methotrexate had no advantage over a weekly schedule. In contrast, a change to every other week dosing was possible in patients stable or in remission on methotrexate, although some experienced disease flares. ${ }^{20}{ }^{21}$ In conclusion, weekly methotrexate is the preferred frequency of administration, with a potential switch to a fortnightly schedule in the case of sustained remission.

In this systematic review, we aimed at finding all available evidence on the optimal dosage and route of methotrexate, by using a strict methodological search and selection strategy. ${ }^{5}$ Furthermore, we limited the search to RCT only, as this design would potentially yield the highest level of evidence without bias from lack of randomisation or blinding, which is associated with observational studies. Moreover, indirect comparisons between methotrexate arms of trials versus placebo, DMARD or anti-tumour necrosis factor, were uninformative in this review, suggesting that observational data would be even more difficult to interpret. In conclusion, eight out of 38 included RCT directly addressed the research question and provided level $1 b-2 b$ evidence for the efficacy and toxicity of various dosages and routes of methotrexate.

In conclusion, taking patient characteristics into account, a start dose of $15 \mathrm{mg} /$ week orally, escalating with $5 \mathrm{mg} / \mathrm{month}$ to 25-30 mg/week or the highest tolerable dose, with a subsequent switch to subcutaneous administration in the case of an insufficient response, seems to be the optimal evidence-based dosing and routing strategy for methotrexate in RA. This conclusion was incorporated as one of the recommendations of the $3 \mathrm{E}$ Initiative for the use of methotrexate in rheumatic diseases. ${ }^{4}$

Acknowledgements: JW Schoones, Walaeus Library, Leiden University Medical Center, The Netherlands, participated in the elaboration of the systematic search strategy. All participants of the $3 E$ Initiative, and especially the bibliographic team, participated in rephrasing the research question, developing the search strategy and planning the analyses.

Funding: The 3E Initiative, including this work, was supported by Abbott with an unrestricted educational grant.

Competing interests: None.

\section{REFERENCES}

1. Aletaha D, Smolen JS. The rheumatoid arthritis patient in the clinic: comparing more than 1,300 consecutive DMARD courses. Rheumatology (Oxford) 2002:41:1367-74.

2. Maetzel A, Wong A, Strand V, Tugwell P, Wells G, Bombardier C. Meta-analysis of treatment termination rates among rheumatoid arthritis patients receiving diseasemodifying anti-rheumatic drugs. Rheumatology (Oxford) 2000;39:975-81.

3. Weinblatt ME. Efficacy of methotrexate in rheumatoid arthritis. Br J Rheumatol 1995;34(suppl 2):43-8.

4. Visser K, Katchamart W, Loza E, Martinez-Lopez JA, Salliot C, Trudeau J, et al Multinational evidence-based recommendations for the use of methotrexate in rheumatic disorders with a focus on rheumatoid arthritis: integrating systematic literature research and expert opinion of a broad international panel of rheumatologists in the 3E Initiative. Ann Rheum Dis 2009;68:1086-93.

5. van Tulder M, Furlan A, Bombardier C, Bouter L. Updated method guidelines for systematic reviews in the Cochrane Collaboration Back Review Group. Spine 2003;28:1290-9

6. Sackett DL, Richardson WS, Rosenberg WM, Haynes RB. Evidence-based medicine: how to practice and teach EBM. London, UK: Churchill Livingstone, 1997.
7. Arnett FC, Edworthy SM, Bloch DA, McShane DJ, Fries JF, Cooper NS, et al. The American Rheumatism Association 1987 revised criteria for the classification of rheumatoid arthritis. Arthritis Rheum 1988;31:315-24.

8. Furst DE, Koehnke R, Burmeister LF, Kohler J, Cargill I. Increasing methotrexate effect with increasing dose in the treatment of resistant rheumatoid arthritis. J Rheumatol 1989;16:313-20.

9. Schnabel A, Reinhold-Keller E, Willmann V, Gross WL. Tolerability of methotrexate starting with 15 or 25 mg/week for rheumatoid arthritis. Rheumatol Int 1994;14:33-8.

10. Verstappen SM, Jacobs JW, van der Veen MJ, Heurkens AH, Schenk Y, Ter Borg EJ, et al. Intensive treatment with methotrexate in early rheumatoid arthritis: aiming for remission. Computer Assisted Management in Early Rheumatoid Arthritis (CAMERA, an open-label strategy trial). Ann Rheum Dis 2007;66:1443-9.

11. Lambert CM, Sandhu S, Lochhead A, Hurst NP, McRorie E, Dhillon V. Dose escalation of parenteral methotrexate in active rheumatoid arthritis that has been unresponsive to conventional doses of methotrexate: a randomized, controlled trial. Arthritis Rheum 2004;50:364-71.

12. Braun J, Kaestner P, Flaxenberg P, Waehrisch J, Hanke P, Demary W, et al. Comparison of the clinical efficacy and safety of subcutaneous versus oral administration of methotrexate in patients with active rheumatoid arthritis. Arthritis Rheum 2008;58:73-81.

13. Gallagher PE, Allen TY, Wyer PC. How to find evidence when you need it, part 3: A clinician's guide to MEDLINE: tricks and special skills. Ann Emerg Med 2002;39:547-51.

14. Glanville JM, Lefebvre C, Miles JN, Camosso-Stefinovic J. How to identify randomized controlled trials in MEDLINE: ten years on. J Med Libr Assoc 2006; $94: 130-6$

15. Oxford Centre for Evidence-based Medicine. Leve/s of evidence. http://www. cebm.net/index.aspx?0=1025 (accessed March 2008).

16. Kazis LE, Anderson JJ, Meenan RF. Effect sizes for interpreting changes in health status. Medical Care 1989;27(3 suppl):S178-89.

17. Cohen J. Statistical power analysis for the behavioral sciences (2nd ed). Hillsdale, $\mathrm{NJ}$ : Erlbaum, 1988

18. Wu JR, Jiang GY, Wei W. Confidence intervals of effect size in randomized comparative parallel-group studies. Stat Med 2006;25:639-51.

19. Pinheiro GR, Helfenstein JM, Ferraz MB, Atra E. A short-term randomized controlled study with methotrexate in rheumatoid arthritis [in Portuguese]. Rev Assoc Med Bras 1993;39:91-4.

20. Kremer JM, Davies JM, Rynes RI, Fink S, Lawrence DA, Petrillo GF, et al. Everyother-week methotrexate in patients with rheumatoid arthritis. A double-blind, placebo-controlled prospective study. Arthritis Rheum 1995;38:601-7.

21. Luis M, Pacheco-Tena C, Cazarin-Barrientos J, Lino-Perez L, Goycochea MV, Vazquez-Mellado J, et al. Comparison of two schedules for administering oral lowdose methotrexate (weekly versus every-other-week) in patients with rheumatoid arthritis in remission: a twenty-four week, single blind, randomized study. Arthritis Rheum 1999;42:2160-5.

22. Pandya S, Aggarwal A, Misra R. Methotrexate twice weekly vs once weekly in rheumatoid arthritis: a pilot double-blind, controlled study. Rheumatol Int 2002;22:1-4

23. Katchamart W, Ortiz Z, Shea B, Tugwell P, Bombardier C. Folic acid and folinic acid for reducing side effects in patients receiving methotrexate for rheumatoid arthritis (an update systematic review and meta-analysis). Arthritis Rheum 2008;58(suppl):S473.

24. Rheumatoid Arthritis Clinical Trial Archive Group. The effect of age and renal function on the efficacy and toxicity of methotrexate in rheumatoid arthritis. J Rheumatol 1995;22:218-23.

25. Jundt JW, Browne BA, Fiocco GP, Steele AD, Mock D. A comparison of low dose methotrexate bioavailability: oral solution, oral tablet, subcutaneous and intramuscular dosing. J Rheumatol 1993;20:1845-9.

26. Hoekstra M, Haagsma C, Neef C, Proost J, Knuif A, van de Laar M. Bioavailability of higher dose methotrexate comparing oral and subcutaneous administration in patients with rheumatoid arthritis. J Rheumatol 2004;31:645-8.

27. Rozin A, Schapira D, Balbir-Gurman A, Braun-Moscovici Y, Markovits D, Militianu D, et al. Relapse of rheumatoid arthritis after substitution of oral for parenteral administration of methotrexate. Ann Rheum Dis 2002;61:756-7.

28. Wegrzyn J, Adeleine P, Miossec P. Better efficacy of methotrexate given by intramuscular injection than orally in patients with rheumatoid arthritis. Ann Rheum Dis 2004;63:1232-4.

29. Furst DE, Breedveld FC, Kalden JR, Smolen JS, Burmester GR, Emery P, et al. Updated consensus statement on biological agents for the treatment of rheumatic diseases, 2006. Ann Rheum Dis 2006;65(Suppl 3):iii2-15.

30. Bannwarth B, Pehourcq F, Schaeverbeke T, Dehais J. Clinical pharmacokinetics of low-dose pulse methotrexate in rheumatoid arthritis. Clin Pharmacokinet 1996;30:194-210. 